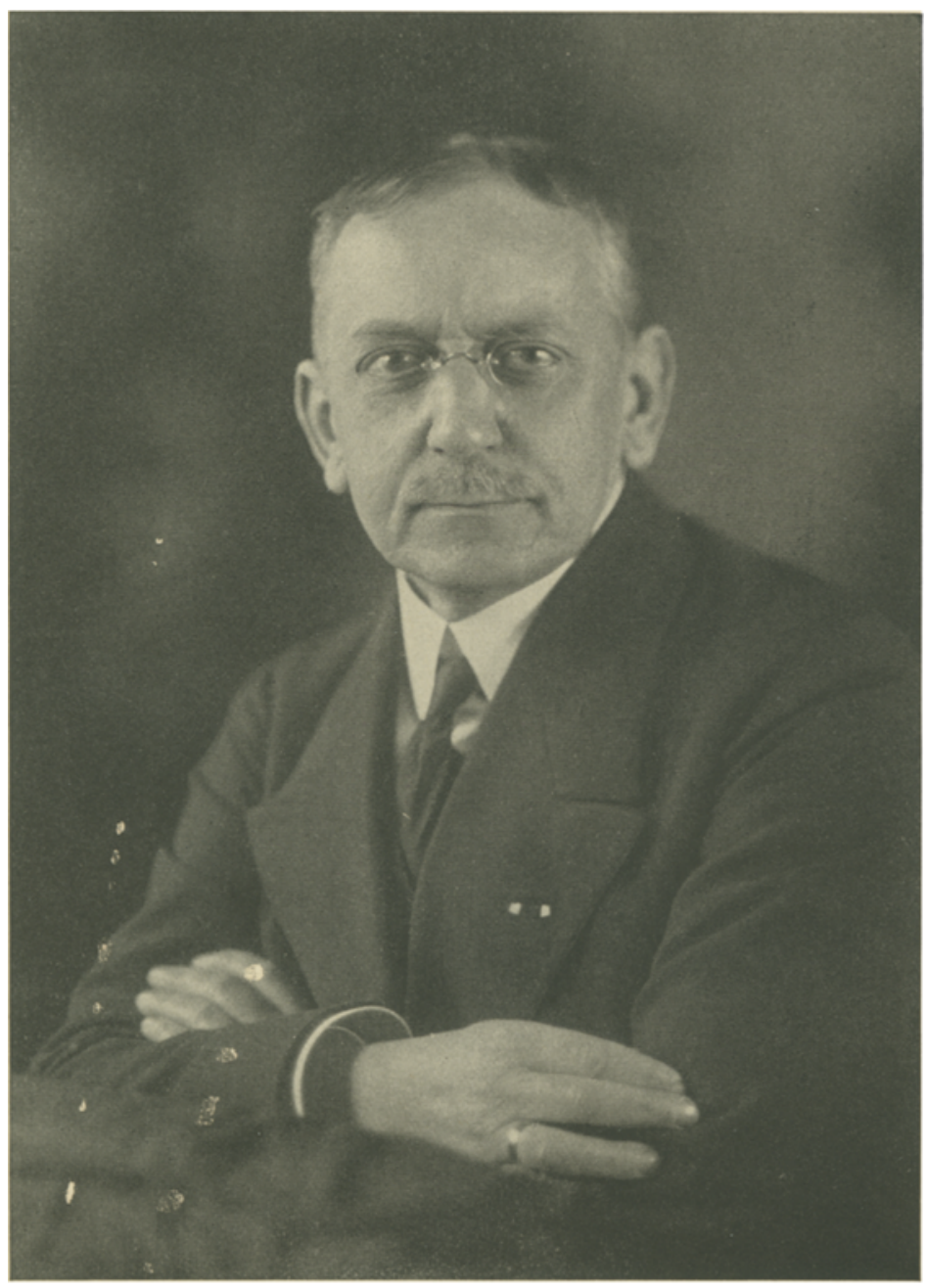

Awolenbry 


\section{Hochverehrter Herr Geheimrat!}

Als wir Mitte vorigen Jahres bei Ihren alten und jungèn Freunden, früheren und jetzigen Assistenten und Schülern Umfrage hielten, ob sie geneigt wären an einer Festschrift zu Ehren Ihres sechzigsten Geburtstages mitzuarbeiten, bekamen wir trotz der Ungunst der Zeiten nur wenige Absagen, und zwar nur da, wo tatsächlich allzu große Berufslasten den betreffenden. Kollegen an der Mitarbeit hindern mußten. Alle andern erklärten sich mit Freuden sofort bereit einen Beitrag zu liefern.

Die Rolle, welche Sie im Leben der einzelnen Mitarbeiter dieser Festschrift gespielt haben, ist eine sehr verschiedene gewesen. Wenn Sie die Reihe der Namen Revue passieren lassen, werden Ihnen diese und jene Phasen Ihrer klinischen Laufbahn und Episoden wieder in aller Deutlichkeit vor Augen treten; und diese epikritischen Betrachtungen Ihrerseits werden sicher mit jener liebenswürdigen Kritik verbunden sein, mit der Sie so geme bei der Hand waren und die einen integrierenden Teil Threr Persönlichkeit darstellt. Wir verdanken Ihnen zahlreiche Anregungen zu kritikvollen, wissenschaftlichen Betrachtungen und Arbeiten. Wir bewunderten stets Ihre Begabung zur klaren Formulierung Ihrer Gedanken, welche gelegentlich auch dichterische Formen annehmen konnten. Thre liebenswürdige Art über die Schwächen Threr Mitarbeiter und Schüler hinwegzusehen, Eitelkeit und Aufdringlichkeit im Zaume zu halten und zurückhaltende Individualitäten zu fördern, alle diese Eigenschaften werden in uns allen, welche Thren Lebensweg gekreuzt haben und mit Ihnen ein Stück Weges gehen durften, in bester Erinnerung bleiben und Sie uns stets verehrungswürdig erscheinen lassen.

Der unglückliche Ausgang des Krieges hat Sie persönlich stärker getroffen als manchen andern und Thnen Ihren schönen Wirkungskreis in unserm geliebten Straßburg genommen, den Sie nie mit einem andern, auch nicht an einer größeren Universität, vertauscht hätten.

Unsere herzlichen Glückwünsche zum 9. Februar schließen den Wunsch in sich, daß Sie in Threm jetzigen Wirkungskreise in Breslau reichen Ersatz für alles Verlorene finden mögen.

Rosenfeld (Rostock). S Steiner (Heidelberg). 